\title{
Is research mediating the relationship between teaching experience and student satisfaction?
}

Universities must ensure that academic staff are qualified and competent for performing their job. Teaching and research are two key activities in which lecturers should excel. While some authors suggest teaching and research complement each other and positively influence student satisfaction, some others point to a rivalry effect between the two.

This study aims at shedding new light on this debate. We first examine the relationship between teaching experience and student satisfaction. In a second stage we explore the mediating effect of research intensity in this relationship. Lastly, we examine potential differences due to contract status. Data gathered in 2014 come from 229 different subjects offered at the Universitat Internacional de Catalunya (Spain).

Our results support the thesis that teaching experience is a determinant of student satisfaction. We also found evidence that current incentive systems at universities are research-biased, negatively impacting on students' perceptions of the teaching received (student satisfaction).

Keywords: higher education, teaching experience, research intensity, student satisfaction, assessment

\section{Introduction}

With the rise of the evaluative state, the assessment of university quality has become a meaningful topic amongst academics and policymakers (Berbegal-Mirabent and Ribeiro-Soriano 2015). Indeed, both public and private bodies, as well as universities, are designing and implementing strategies to ensure a proper performance of higher education institutions in their daily activities.

Different types of evaluations are envisioned; however, those adopting a lecturer-centred approach are gaining popularity. Lecturers are in charge of teaching 
students but also of actively participating in research activities. This suggests that both teaching and research quality are in their hands (Bentley et al. 2013). Given this high degree of responsibility that lecturers have acquired, university managers must ensure that lecturers are qualified and competent for their job. Teaching and research are the two categories of academic work for which faculties are usually evaluated (Teichler 2014; Locke 2012). Different attempts and measuring systems are found in abundance, however there is a fierce debate concerning the suitability of the proxies used to evaluate each type of activity.

Indeed, the relationship between teaching and research activities is a controversial issue in the field of higher education management (Halse et al. 2007; Robertson and Bond, 2005). Over the years, teaching and research functions have increasingly acquired separate identities, and nowadays there is as growing awareness that they have become separate activities of faculty work (Barnett, 2005; Jenkins and Zetter, 2003). However, when both activities are viewed from the standpoint of a learning process, they are expected to be mutually reinforcing (Burke and Rau 2010; Becker and Kennedy 2005; Brew 2003).

Previous studies examining the trade-offs between teaching and research activities have reported different results (Durning and Jenkins 2005), providing welljustified arguments for a positive, negative and even a null effect. However, to the best of the authors' knowledge, the literature is inconclusive regarding how student satisfaction is determined by lecturers' performance in these two activities.

Students' choice is found to be highly influenced by teaching experience and the university's prestige (which is related to research quality) (Gibbons, Neumayer, and Perkins 2015; Gautier and Wauthy 2007). Because students are one of the main customers of the higher education system (Woodall, Hiller, and Resnick 2014), in this 
study we examine how faculty members' previous teaching and research achievements shape student satisfaction. We posit that previous teaching experience positively influences student satisfaction. Nevertheless, we argue that this relationship is mediated by the research intensity of the lecturer. Aiming at exploring these relationships, we propose an exploratory analysis based on the specific case of the Universitat Internacional de Catalunya, a private university in Barcelona (Catalonia, Spain).

The remainder of the paper is organised as follows. We first review the literature on the potential trade-offs between teaching and research activities. The next section provides the theoretical framework and the development of the hypotheses. After this, we describe how constructs are operationalised and the methodological approach used. Results are reported in the next section. The discussion of the findings and concluding remarks are put forward in the last section.

\section{The teaching/ research nexus paradigm}

Most higher education systems expect lecturers to excel at both teaching and research activities. Literature examining the tensions between the teaching and research role of lecturers is rich, although unclear. Figure 1 summarises the three main scenarios reported in the literature.

Figure 1 to be inserted here

A positive relationship is assumed if we look at the abilities underlying good teaching and successful research. Attitudes, values and competencies that lead to teaching excellence are also likely to lead to high-quality research (uz Zaman 2004). Both teaching and research activities require the lecturer to be creative (e.g. imaginative, original, inventive), highly committed with his/her tasks (e.g. show 
perseverance, dedication, hard work), possess critical analysis, and be good in disseminating and communicating knowledge (Hattie and Marsh 1996). Reinforcing effects between teaching and research are thus accepted in both directions (Shin 2011). On the one hand, research contributes to improving teaching because research-active lecturers are at the cutting-edge of their field, which translates into more accurate and up-to-date material that captures more easily the students' attention (Marsh and Hattie 2002). Likewise, presenting the researcher's own material adds a sense of authenticity that differs from presentations where lecturers discuss the work of others with neither passion nor an active involvement (uz Zaman 2004). On the other hand, there are also claims that research benefits from teaching. Preparation of teaching materials as well as students' suggestions in class may help identify gaps in the literature and detect new research directions (Coate, Barnett, and Williams 2001). Also, sharing the results of one's research efforts with an appreciative audience provides priceless feedback that could be used to improve research outcomes. All in all, these studies indicate that there are a number of ways in which knowledge production and student learning can be brought together (Griffiths 2004). Nevertheless, following Robertson (2007), in order to mutually reinforce each other, the teaching/research nexus needs to be expanded and include the phenomena of learning, knowledge and their interrelation.

A second group of studies argue that teaching and research are conflicting activities, pointing to a negative relationship between them (Parker 2008; Serow 2000). A divergent reward system model is one of the main arguments supporting this thesis (Hattie and Marsh 1996). Both teaching and research are time-consuming activities. As time is a scarce resource, faculty members tend to prioritize those activities that are going to bring them a greater benefit, a benefit which is usually measured in terms of stability within the academia. Considering the weight given to research outputs in 
evaluation processes for tenure and promotion, young academics who need to carve out an academic career are more likely to reduce the time and effort spent on teaching in favour of research, as this long-distance race is conditioned, to a great extent, to their research capability (Marsh and Hattie 2002). Likewise, faculty members might also be tempted to spend their time on research activities in detriment to teaching ones because research may entail contracts with third parties, implying additional revenues. In this respect, teaching does not usually significantly contribute towards overall salary (uz Zaman 2004).

Finally, teaching and research have also been considered as separate activities which have little impact on each other (Noser, Manakyan and Tanner 1996; Ramsden and Moses 1992). Authors supporting this premise claim that in some research centres where there is no teaching, higher quality research is performed (Ramsden and Moses 1992). This means that teaching and research could be considered independently. Another argument holds that these activities are different enterprises because they involve different tasks, which in turn require different preparation and personality traits (Shin 2011). While teaching concentrates on the transmission of knowledge, research stresses the discovery of knowledge. An effective teacher may not be an effective researcher, and vice versa. As a result, one might expect a zero effect between these two activities.

\section{Theoretical framework and hypotheses development}

\section{Teaching experience}

If a lecturer is committed to teaching excellence, his/her work will be highly valued by students (Xiao and Wilkins 2015). The underlying rationale behind this argument is that irrespective of the teaching experience, those lecturers who are good 
communicators, motivated and feel what they teach, are concerned with an effective student learning, consequently they are interested in improving their teaching skills and can obtain high records in students' evaluations.

Although both youth (young lecturers) and maturity (senior faculty) can generate an interesting teaching, there is however widespread consensus regarding the positive relationship between the years of teaching experience and teaching performance (Drule et al. 2014). While in the early career stages lecturers might be concentrated on defining the objectives and the content of the course, until the lecturer achieves teaching maturity, he/she will not really experiment in-depth with different learning methods and fully engage students in their learning process.

Certainly, experience is the father of wisdom. Previous experience gives academics the tips and tricks on how to better attract students' attention, which consequently increases their satisfaction with the course. Novice lecturers and doctoral students who have to perform teaching duties are thus in a disadvantaged position. Aiming at compensating for this lack of experience, they usually take formal courses on teacher training (Gibbs and Coffey 2004).

Previous studies examining the impact of teaching experience on student satisfaction is quite limited. For the purpose of this study, the works of Prieto and Altmaier (1994) and Shannon, Twale, and Moore (1998) are noteworthy. These authors examined the influence of previous teaching experience on graduate students at university and found that those lecturers with previous teaching experience rated more positively than those without such teaching experience. More recently, Madsen and Cassidy (2005) examined how different levels of teaching experience affect perceptions of teaching effectiveness and student learning, concluding that teaching experience does 
have an impact on students' perceptions of teaching quality. Accordingly, we hypothesise:

Hypothesis 1: Previous teaching experience positively influences student satisfaction.

\section{The mediating role of research intensity}

Considering the teaching/research tensions described in the literature, one may argue that because time is a scarce resource, lecturers might manage it according to their interests and needs (Gautier and Wauthy 2007). It is thus reasonable to suggest that the relationship between teaching experience and student satisfaction might be mediated by the commitment of the lecturer to performing research activities. A second hypothesis emerges:

Hypothesis 2: Research intensity mediates the relationship between teaching experience and student satisfaction.

Figure 2 graphically illustrates the two models to be tested.

Figure 2 to be inserted here

\section{Stability}

Furthermore, we put forward that the commitment to teaching and research activities undergo significant fluctuations throughout the academic life of a lecturer. Curriculums are usually driven by research interests, therefore during the first career stages, research will occupy most of the lecturer's time (Boardman and Ponomariov 2007). This may lead academics to be less available for students and less concerned about their opinions and educational needs. These situations are undoubtedly perceived by students, 
increasing a sense of carelessness towards teaching that can generate dissatisfaction.

As a lecturer advances in their academic career, two main different behavioural paths are envisioned. The first pattern is followed by researchers aimed at building a solid research reputation. Herein, the pressure for producing and disseminating research outputs might have transformed into something vocational, but much more demanding as research projects tend to rapidly increase in scale. The second pattern is shaped by obligations. Seniority within academia tends to involve holding academic posts that entail some degree of responsibility (i.e. head of the department, deputy head of faculty, dean, etc.). Regardless of the pattern followed, in both cases teaching is relegated to second place. However, we argue that because of the teaching experience they have gained over the years, they are able to compensate for the limited time devoted to teaching activities, and consequently obtain better results in student satisfaction surveys than young researchers. Due to the fact that the current academic development career system does not provide stability for lecturers who do not show a minimum performance in research, after a few years a lecturer must either achieve a permanent contract or be dismissed. Consequently, young academics are mainly in fixed-term positions, whereas senior academics enjoy the security of permanent contracts. Accordingly, our last hypothesis follows:

Hypothesis 3: There are significant differences between permanent staff and non-permanent staff in terms of the mediating effect of research intensity in the relationship between teaching experience and student satisfaction.

\section{Methodology}

\section{Sample}

For the purposes of this study, 1077 different subjects offered at the Universitat 
Internacional de Catalunya (UIC) were considered. Data were collected during the first term of the 2014/15 academic year. After filtering in order to obtain records with the complete information required for our study, 229 valid subjects remained. Note that the unit of analysis is the subject, and for each subject we then gathered information about the corresponding lecturer. No bias gender was detected. Table 1 shows the main characteristics of the sample.

Table 1 to be inserted here

\section{Measures}

\section{Student satisfaction}

The student voice is now being heard more than ever. Students are the direct recipients of university teaching, becoming primary consumers of the higher education system. They have the most first-hand information concerning their instructors' teaching performance (uz Zaman 2004), therefore asking them directly about their perceptions of teaching effectiveness is crucial.

A common practice for obtaining students' perceptions of lecturers consists of the use of surveys, where students are asked to fill in an evaluation sheet. Questions typically refer to those characteristics that have been found to describe what constitutes an effective teacher: whether the lecturer is knowledgeable about, demonstrates a strong interest in the subject, is organised and prepared for class, is able to assist with and encourage student learning, is dynamic in the classroom with effective presentation skills, or is fair and equitable in the evaluation of students. The reliability and internal validity of these instruments has been tested and there is a consensus among academics 
that data obtained through these instruments is consistent (Gravestock and Greenleaf 2008; Kulik 2001) and essential for a comprehensive evaluation of university quality (Seldin 2006, 2004).

At this point, it is worth highlighting that responses coming from students' surveys capture whether faculty members are interested in and committed to their teaching activities regardless of the academic position held by the instructor. In fact, students are rarely aware of how the academic career and the promotion system work. Because of this characteristic, student satisfaction surveys are very attractive.

According to Pratt (1997) student satisfaction surveys have to consider three aspects of teaching: organisation and planning (reading list, timing and workload); implementation and interaction (technical skills and class management); and results (learning outcomes and effectiveness). In this respect, UIC created a scale to fulfil these requirements. The questionnaire contains 10 items and employs a five-point Likert scale. It was validated in 2007 for two subjects from the two different campuses of the university. The 10 items are grouped in: (i) organisation and planning, items 1-3; (ii) implementation and group interaction, items 4-9; and (iii) results, item 10. Table 2 contains the full scale.

Table 2 to be inserted here

\section{Control variables}

There are, however, a number of additional factors shaping student satisfaction that need to be controlled. First, we control for gender invariances. Second, we differentiate by knowledge field (Lindblom-Ylänne et al. 2006). Taking into account the academic offering at UIC, there are four main disciplines: architecture, health sciences, 
social and law sciences, and humanities. Third, we distinguish between undergraduate and master level (Coate, Barnett, and Williams 2001; Noser, Manakyan, and Tanner 1996).

Several are the voices that claim that despite the proliferation of student satisfaction surveys, a combination of multiple sources can provide a more accurate, reliable and comprehensive picture of teaching than just one sole source (Berk 2005). In this context, evidences from the lecturer and reports elaborated by peers constitute other ways of gathering valuable information (Seldin 2006) that can help in identifying areas of improvement, which students are not yet able to perceive (uz Zaman 2004). We thus introduced a fourth control variable, and examined whether the results of the internal teaching assessment performed by the university are consistent with students' opinions. We argue that if this assessment procedure is found to have a positive and significant influence in our model, it would mean that the internal assessment procedure is aligned with students' opinions, strengthening the importance of this mechanism as a complementary method for gathering essential information on how lecturers perform in terms of teaching activities.

At UIC the Department of Innovation and Educational Quality is in charge of perming this assessment. Evaluations range from unfavourable, favourable with conditions, favourable, or highly favourable. A combination of multiple evidences is used to determine the level of teaching quality: (i) a report elaborated by the head of the department; (ii) a self-assessment report, providing a reflective appraisal of how the instructor has designed and delivered the course (this report is usually complemented with examples of course materials and sample student assignments); and (iii) an in-class evaluation performed by another professor. 


\section{Teaching experience}

Teaching experience has been measured by the number of years that a lecturer has been teaching at UIC. We acknowledge the limitation of using this metric, as it does not capture previous teaching experience of the lecturer in other universities prior to joining

UIC. Unfortunately, it was not possible to obtain this information, consequently we only account for years of teaching experience at UIC.

\section{Research intensity}

Regarding research metrics, common indicators tend to use bibliometric data (Sarrico et al. 2010). Information of this type is widely available, including measures such as the number of papers published in scientific journals indexed in specific databases and the number of citation counts. All these metrics are accepted to reflect both the quantity and quality of the research activity (Abramo, D'Angelo, and Pugini 2008). However, these variables are usually criticised because they can be influenced by self-citation and friend-citation practices (Toutkoushian et al. 2003) and are incomplete (Van Raan 2005), representing and incomplete picture of the research dimension.

Recent studies suggest that a more convenient measure of research intensity would be one including weighted composites of different research results (Turner 2005). While some academics suggest that aggregate dimensions can be obviated for introducing biases (weights are not objective) and not being a substantive basis in the literature for making such judgments (Salerno 2004), other authors argue that only composite indices can really reflect research quality (Tyagi, Yadav, and Singh 2009).

Similar to composite indicators are the assessments of academic staff performed by external agencies. Quality assurance criteria and guidelines in the European Higher Education Area are sponsored by the European Association for Quality Assurance in 
Higher Education (ENQA) and include the assessment of academic staff. Although these procedures entail a holistic evaluation of academics' performance, they tend to be research-biased. Consequently, the assessment they provide is much more able to reflect research activities than teaching ones. Although there is no empirical evidence of a correlation between research intensity and the results of these assessment processes, we consider that this mechanism for evaluating lecturers' research credentials does reflect the research activity, as for the most part, these evaluation procedures take into consideration research outputs in its multiple forms (i.e. publications in ISI journals, competitive research projects, thesis directed, books and book chapters).

In Catalonia, there are two external agencies in charge of performing this assessment process: the Catalan University Quality Assurance Agency (AQU), acting at the regional level, and the National Agency for Quality Assessment and Accreditation of Spain (ANECA), covering the whole Spanish territory. When a Catalan university needs to replenish a vacant position, it takes into account whether the candidate holds any of the accreditations issued by either AQU or ANECA. Although both agencies are operating under the same European principles, they use their own standards and the names of the resulting categories (according to the level of achievement) are also diverse.

Table 3 summarises the main academic categories that exist in the Catalan higher education system. The category in the first row indicates that the lecturer is still in his/her initial stage so that his/her research outputs are reduced (in terms of publications, conferences, research projects, patents, etc.). On the contrary, the last row represents a lecturer with a solid career, accordingly research outputs are numerous and of high quality. 
Table 3 to be inserted here

Aiming at overcoming some of the drawbacks of the different metrics summarised above, for the purpose of this study research intensity has been operationalised through a 7-point scale, according to the category of each lecturer.

\section{Stability}

The type of contract, permanent or fixed-term, has also been shown to drive lecturers' decisions on which activities to dedicate more time and effort to (Shin 2011; Coate, Barnett, and Williams 2001). At UIC, the academic career begins with a fixed-term contract. Internal promotion policies are tied to research achievements; therefore, as the lecturer attains higher research accreditations, he/she is given the opportunity to apply for a permanent position. In addition to having a more stable relationship with the university, permanent positions are better remunerated. Aiming at examining the effect of stability in our model, a variable capturing the type of contract (fixed-term or permanent) is used.

\section{Method}

The empirical application is divided into three main stages. The first one consists of assessing the psychometric features of the scale used to assess student satisfaction. The reliability and internal consistency of the two subscales of student satisfaction ('organisation and planning' and 'implementation and interaction') are thus analysed. 'Results' is the third dimension of student satisfaction; however, as this dimension is collected in only one item, there is no need to assess its internal consistency. In order to better understand the student satisfaction construct, we next analyse potential differences in its dimensions, attending to a series of factors that might divide the 
sample into different subgroups. Using the factors identified in the previous section as control variables, we perform several non-parametric tests. For dummy variables (i.e. gender and study level), the Mann-Whitney U test was conducted. The null hypothesis is that the two samples come from the same population against an alternative hypothesis. For those variables with more than two categories, the equivalent nonparametric test is the Kruskall-Wallis test (i.e. knowledge area and internal teaching assessment), which extends the Mann-Whitney U test to more than two groups.

In the second stage we analyse the relationship between teaching experience and student satisfaction. We also test the mediating effect of research intensity in the aforementioned relationship. For this purpose, we adopt the methodology suggested by Baron and Kenny (1986) and revised by Zhao, Lynch, and Chen (2010), using structural equation modelling (SEM). According to Preacher and Hayes (2004) it is preferable to use SEM for assessing mediation because it offers a reasonable way to control for measurement error as well as some interesting alternative ways to explore the mediating effect.

Lastly, in the third stage we perform a multigroup analysis to test the existence of diverse behavioural paths due to the type of contract (fixed-term or permanent). This method is appropriate for testing whether both the factor structure and the factor loadings are invariant.

\section{Results}

\section{Psychometric features of the student satisfaction construct}

A confirmatory factor analysis (CFA) was conducted with the three items of the 'organisation and planning' dimension and another CFA with the six items that measure 'implementation and interaction'. The CFAs were estimated by using the robust 
maximum likelihood method from the asymptotic variance-covariance matrix. Each CFA extracted only one factor, confirming the unidimensionality of both dimensions. Validity of individual items was confirmed (0.781-0.963). The internal consistency of the two dimensions was analysed through Cronbach's alpha and the composite reliability. Additionally, the convergent validity was probed with the average variance extracted (AVE) and with the high robustness of the loads, all significant at 0.05 level (see Table 4).

Table 4 to be inserted here

The next step consisted of the analysis of a third CFA to assess the 'student satisfaction' construct as a whole, that is, including the two aforementioned dimensions together with a third dimension composed by only one item that accounts for the 'results' (item 10). The Satorra-Bentler scaled at $\chi^{2}=81.80$ with 33 degrees of freedom $(p$-value $=0.00001)$, alongside a CFI of 0.935 and a root mean-square error of approximation $(\mathrm{RMSEA})=0.081$ vouched for the fit of the data.

It is worth mentioning that the correlations among the three dimensions are rather high, giving rise to some concerns about the discriminant power of the three concepts. Nevertheless, we rely on these dimensions as their design is supported by the literature and because of the fit of the model, which has been proved to be appropriate.

\section{Factors shaping student satisfaction}

In order to analyse differences in the distribution of the dimensions of the student satisfaction construct, four non-parametric tests were conducted. Results are displayed in Table 5, revealing that there are some factors, namely knowledge field and internal 
teaching assessment that point to significant differences. As for the former, the best results are achieved in the fields of health sciences (average value: 4.2864) and architecture (average value: 4.1430). Further studies should examine the use of different teaching methods to better understand these differences. Concerning the internal teaching assessment, results confirm that those lecturers that obtained a higher score in this internal assessment procedure also obtain better results in terms of student satisfaction records. No differences are found by study level or gender.

Table 5 to be inserted here

\section{Mediating effect of research intensity}

In order to proceed with the analysis of the mediating effect, two SEM were conducted, one for each of the models illustrated in Figure 1. Results are presented in Table 6.

Table 6 to be inserted here

By using a row of three regression analyses, Baron and Kenny (1986) ascertained that three conditions must hold in order to establish mediation. Similar to Preacher and Hayes (2004), we express these conditions in terms of SEM as follows (note that only two SEMs are needed: one for the total effect [c'] and a second SEM for simultaneously assessing the direct effect [c] and the indirect effect [a*b]): The first condition is that the independent variable (teaching experience) has to significantly predict the mediator (research intensity) in Model $1 \mathrm{~b}$ (i.e. $\mathrm{a} \neq 0$, Table 6 ). The second requirement states that the independent variable (teaching experience) must predict the dependent variable (student satisfaction) in Model 1a (i.e. $c^{\prime} \neq 0$, Table 6). Lastly, the 
third condition is that the mediator (research intensity) must significantly predict the dependent variable (student satisfaction) (i.e. $b \neq 0$, Table 6 ) controlling for the independent variable (i.e., $\mathrm{c} \neq 0$, Table 6 ) in Model $1 \mathrm{~b}$.

For the purpose of our study, the second condition is not satisfied since the coefficient is not significant ( $\mathrm{t}$-value $=1.449)$. However, Zhao, Lynch, and Chen (2010) argue that this condition is not necessary. These authors demonstrate that there is only one requirement to establish mediation: the indirect effect $\mathrm{a}^{*} \mathrm{~b}$ should be significant. Preacher and Hayes (2004) also provide methodology for this case, based on the work of Sobel (1982). Relying on the empirical demonstrations provided by these authors, we thus proceed with the analysis, and observe that the critical ratio for the indirect effect is $\mathrm{t}=-3.412$, confirming the significance of the indirect effect and vouching for the subsequent analysis.

Based on the typologies of mediation characterised by Zhao, Lynch and Chen (2010), our case responds to that of a competitive mediation, as it accomplishes the following three conditions: (i) $a^{*} b$ is significant; (ii) $c$ is significant; and (iii) $a^{*} b^{*} c$ is not positive. Thus, both the mediating effect $\left(a^{*} b\right)$ and the direct effect (c) exist, however, they point to different directions. Particularly, the total effect of teaching experience on student satisfaction $\left(c^{\prime}=0.086\right.$, not significant) is explained through the direct effect $(c=0.210)$ and the indirect effect $(a * b=-0.124)$. Both effects are statistically significant, therefore, giving support to hypothesis 1 . This translates into saying that, as expected, teaching experience positively impacts student satisfaction, reinforcing the argument that experience gives lecturers the skills and techniques that allow them to better communicate and interact with students, resulting in higher satisfaction rates from students. In addition, our results confirm that experience also leads to increased levels of research intensity, which negatively impact on student 
satisfaction. There is, therefore, empirical evidence that research intensity mediates the relationship between teaching experience and student satisfaction, validating hypothesis 2.

These findings bring to light a genuine dilemma for university managers. On the one hand, the reputation of a university is highly linked to research achievements, which are key determinants for obtaining a good positioning in popular rankings. Likewise, evaluation processes conducted by governmental bodies to validate the academic offering of universities (i.e. undergraduate, postgraduate, master and doctoral level) also mainly rely on the quality and quantity of the research output of the academic staff. In addition, the academic career and internal promotion policies are also research-biased. All in all, this situation brings research activities into the spotlight. Research is highly instilled in the university and the future of the university is dependent on research. However, on the other hand, private universities (such as the case under analysis) need to stand out for the quality of their teaching, as for the most part income stems from students' tuition fees.

\section{Testing the influence of contract type}

A multigroup analysis of Model $1 \mathrm{~b}$ to test invariance between the two categories of labour contract type (fixed-term and permanent) was performed. The number of academics [in our sample] with a temporary contract is 123 , and that of those enjoying a permanent relationship with the university is 106 . We posit that different strategies are going to be observed as a consequence of the duality of the lecturer's career. Depending on the stabilization stage and personal motivations, lecturers might follow different strategies in the way they allocate time and efforts to teaching and research activities. The model is estimated using the robust maximum likelihood method from the asymptotic variance-covariance matrix. Five constraints were established accounting 
for the invariance of the structural paths of the model. It is important to remark that the parameter between the 'organisation and planning' dimension and the second order factor of the student satisfaction construct is fixed to a constant in order to fix the scale; consequently, it cannot be imposed as a restriction.

The fit indices are satisfactory: $\chi^{2}$ Satorra-Bentler was 205.92, with 107 degrees of freedom, $\chi^{2} / \mathrm{df}$ was 1.92 , which was below the acceptable limit of 5 , RMSEA was 0.090 and the CFI was 0.913 . To locate parameters that are non-invariant across groups, we looked for probability values associated with the incremental univariate $\chi^{2}$ values that are $<0.05$. A review of these values reveals that all parameters operate equivalently across fixed-term and permanent staff, excepting the parameter that links the research intensity with student satisfaction. Table 7 reports both the standardised and nonstandardised paths. The non-standardised have been constrained to be equal.

Table 7 to be inserted here

Hypothesis 3 is partially accepted as the only difference between fixed-term and permanent staff is the path between research intensity and student satisfaction. This path is statistically significant and more negative for permanent staff. This result suggests that apparently, academics that have reached a high level of research activity are, however, abandoning their teaching responsibilities. Several factors might explain this behaviour. First, the higher the research level an academic attains, the higher the likelihood to get involved in more demanding research projects. Second, reaching a permanent position at the university entails less uncertainty and thus, job security, leading to a potential 'relaxation' situation. This statement particularly holds in terms of teaching tasks. As academics consolidate their careers, promotion to superior positions 
are mainly determined by research achievements, providing a clear inducement for lecturers to become careless in their teaching in favour of research. Incentives for conducting high-quality teaching are only subject to the willingness of the lecturer to improve his/her teaching skills.

\section{Discussion}

Herein we have analysed the relationship between teaching experience and student satisfaction and the mediation effect of research intensity. Based on our results, we can conclude that, for the sample considered, the research effort strongly 'competes' with teaching commitment. From the standpoint of a university that strives to survive in a competitive and global environment, the research mission is essential. Therefore, the production of high-quality research outcomes is a clear objective in its strategic planning. Nevertheless, from the students' perspective, high-quality teaching is paramount to ensure positive word-of-mouth recommendations and to generate brand awareness. As tuition fees are important for sustaining the economic viability of private universities, the teaching mission is another objective that needs to be accomplished. How to appropriately balance teaching and research is still the key to success. Unfortunately, there is no magic formula for how to do it.

In terms of policy implications, we argue that promotion incentives are central to the teaching/research nexus debate. It is well documented that research has outranked teaching in the university's faculty reward system (Parker 2008). Indeed, reward structures (including tenure, promotion and faculty salaries) are clearly favouring research activities over teaching ones (Fairweather 2005). Many academics attributed this to the impact of university rankings, which prompted universities to accentuate the importance of research (Taylor 2007). Additionally, research outcomes are much easier to be quantified and compared than those of teaching. 
Incentives are clearly affected by the career stage of the lecturer (Baldwin, Lunceford and Vanderlinden 2005). Academics in a weaker contractual position would have stronger incentives to conduct research in order to create reputational signals that are expected to increase their probability of being appointed by universities. Conversely, full professors have less exogenous incentives to make visible their research, their only motivation being endogenously determined by their own interest in strengthening their curriculum vitae. Moreover, when looking at the specific weight that promotion assessments assign to the teaching dimension of academic quality, we can observe that it tends to be undervalued. Indeed, maintaining a minimum standard in student satisfaction surveys appears to be enough. Consequently, instructors that are in their initial stages would not have such a strong incentive to deliver good lectures as they do for conducting quality research.

All in all, this situation leads us to conclude that current accreditation systems are not obtaining the expected results in terms of student satisfaction. While teaching and research activities should complement and enrich each other, empirical evidence suggests that students perceive disadvantages in staff involvement in research activities. In this respect, previous studies indicate that those academics whose research efforts are in areas strongly related to their teaching may be favoured in comparison to their counterparts, for whom it is more difficult to incorporate knowledge into their classroom practice (Shin 2011). In view of that, we argue that more emphasis should be placed on trying to align the teaching workload with the research interests of lecturers. We acknowledge that in some disciplines, and depending on the academic offering of the university, this task might not be an easy one. Nevertheless, given the pressure to which academics are subjected, it seems reasonable to try to facilitate their tasks by narrowing the gap between teaching duties and research interests. This way, it would be 
possible to obtain economies of scale, so that the efforts spent performing teaching activities are also useful in terms of research, and vice versa.

\section{Concluding remarks}

Universities are expected to be centres of high-quality education and hubs of research and innovation. Therefore, examining how student satisfaction is shaped by the profile of the lecturer (teaching or research-oriented) is of great interest. In view of this, the present paper contributes to the existing literature that investigates the trade-offs between teaching and research activities, responding to the call of previous studies to examine in-depth this particular matter. In particular, our study examines the relationship between teaching experience and student satisfaction, and the mediating effect of research intensity in this association. In addition, we explore the potential dissimilarities in this relationship due to academic status (permanent staff and nonpermanent staff).

High-quality teaching and high levels of research intensity are both desirable outcomes. Certainly, universities would like their lecturers to excel in both dimensions, nevertheless very little is known about how to effectively accomplish this ideal. We encourage future studies to examine which mechanisms or incentive schemes could be articulated in order to motivate lecturers to equally engage in both teaching and research activities.

Probably the main limitation of this study relates to the specific analysis of a Catalan private university and the reduced sample considered. Future studies should be conducted with larger samples and in other universities with a similar regulatory framework. Another limitation deals with the measures selected to capture teaching experience and research intensity. Although it was possible to create valid and reliable measures that considered viewpoints from different stakeholders, university quality is a 
broad term, which, while in theoretical models seems to be relatively easy to be measured, is constrained in its practical operationalisation by the feasibility of obtaining appropriate data.

\section{References}

Abramo, G., C. A. D’Angelo, and F. Pugini. 2008. "The measurement of Italian universities' research productivity by a non parametric-bibliometric methodology." Scientometrics 76, no. 2: 225-244.

Baldwin, R. G., C. J. Lunceford, and K. E. Vanderlinden. 2005. "Faculty in the middle years: Illuminating an overlooked phase of academic life." The Review of Higher Education 29, no. 1: 97-118.

Barnett, R. 2005. Reshaping the university: New relationships between research, scholarship and teaching. Maidenhead, UK: Open University Press.

Baron, R. M., and D.A. Kenny. 1986. "The moderator-mediator variable distinction in Social Psychological Research: Conceptual, Strategic, and Statistical Considerations." Journal of Personality and Social Psychology 51, no. 6: 11731182.

Becker, W. E., and P. E. Kennedy. 2005. "Does teaching enhance research in economics?" American Economic Review 95, no. 2: 172-176.

Bentley, P. J., Coates, H., Dobson, I. R., Goedegebuure, L., and Meek, V. L. (2013). Job satisfaction around the academic world. The Netherlands: Springer.

Berbegal-Mirabent, J., and D. E. Ribeiro-Soriano. 2015. "Behind league tables and ranking systems: A critical perspective of how university quality is measured." Journal of Service Theory and Practice 25, no. 3: 242-266.

Berk, R. A. 2005. "Survey of 12 strategies to measure teaching effectiveness." International Journal of Teaching and Learning in Higher Education 17, no. 1: $48-62$.

Boardman, P. C., and B. L. Ponomariov, 2007. "Reward systems and NSF university research centers: The impact of tenure on university scientists' valuation of applied and commercially relevant research.” Journal of Higher Education 78, no. $1: 51-70$. 
Brew, A. 2003. "Teaching and research: New relationships and their implications for inquiry-based teaching and learning in higher education." Higher Education Research and Development 22, no. 1: 3-18.

Burke, L. A., and B. Rau. 2010. "The research-teaching gap in management." Academy of Management Learning \& Education 9, no. 1: 132-143.

Coate, K., R. Barnett, and G. Williams. 2001. "Relationships between teaching and research in higher education in England." Higher Education Quarterly 55, no. 2: $158-174$.

Drule, A. M., I. E. Popa, R. Nistor, and A. Chis. 2014. "Quality of the teaching process and its factors of influence from the perspective of future business specialists." The AMFITEATRU ECONOMIC Journal 16, no. 37: 827-840.

Durning, B., and A. Jenkins. 2005. "Teaching/Research relationships in departments: The perspective of built environment academics." Studies in Higher Education 30, no. 4: 407-426.

Fairweather, J.S. 2005. "Beyond therhetoric: Trends in the relative value of teaching and research in faculty salaries." The Journal of Higher Education 76, no. 4: $401-422$.

Gautier, A., and X. Wauthy.2007. "Teaching versus research: A multi-tasking approach to multi-department universities." European Economic Review 51, no. 2: 273295.

Gibbons, S., E. Neumayer, and R. Perkins. 2015. Student satisfaction, league tables and university applications: Evidence from Britain. Economics of Education Review 48: 148-164.

Gibbs, G., and Coffey, M. (2004). "The Impact of training of university teachers on their teaching skills, their approach to teaching and the approach to learning of their students." Active Learning in Higher Education 5, no. 1: 87-100.

Gravestock, P., and Gregor E. Greenleaf, 2008. Student course evaluations: Research, models and trends. Toronto, ON: Higher Education Quality Council of Ontario.

Griffiths, R. 2004. "Knowledge production and the research-teaching nexus: The case of the built environment disciplines." Studies in Higher Education 29, no. 6: 709-726. 
Halse, C., E. Deane, J. Hobson, and G. Jones. 2007. "The research-teaching nexus: What do national teaching awards tell us?" Studies in Higher Education 32, no. 6: 727-746.

Hattie, J., and H. W. Marsh. 1996. "The relationship between research and teaching: A meta-analysis." Review of Educational Research 66, no. 4: 507-542.

Jenkins, A., and R. Zetter. 2003. Linking research and teaching in departments. Learning and Teaching Support Network (LTSN). UK: Oxford Brookes University.

Kulik, J. A. 2001. "Student ratings: Validity, utility, and controversy." New Directions for Institutional Research 2001, no. 109: 9-25.

Lindblom-Ylänne, S., K. Trigwell, A. Nevgi, and P. Ashwin, 2006. "How approaches to teaching are affected by discipline and teaching context." Studies in Higher Education 31, no. 3: 285-298.

Locke, W. 2012. "The dislocation of teaching and research and the reconfiguring of academic work." London Review of Education 10, no. 3: 261-274.

Madsen, K., and J. W. Cassidy. 2005. "The effect of focus of attention and teaching experience on perceptions of teaching effectiveness and student learning." Journal of Research in Music Education 53, no. 3: 222-233.

Marsh, H. W., and J. Hattie. 2002. "The relation between research productivity and teaching effectiveness: Complementary, antagonistic, or independent constructs?" Journal of Higher Education 73, no. 5: 603-641.

Noser, T. C., H. Manakyan, and J. R. Tanner. 1996. "Research productivity and perceived teaching effectiveness: A survey of economics faculty." Research in Higher Education 37, no. 3: 299-321.

Parker, J. 2008. "Comparing research and teaching in university promotion criteria." Higher Education Quarterly 62, no. 3: 237-251.

Pratt, D. D. 1997. "Reconceptualizing the evaluation of teaching in higher education." Higher Education 34, no. 1: 23-44.

Preacher, K. J., and A. F. Hayes, 2004. "SPSS and SAS procedures for estimating indirect effects in simple mediation models." Behavior Research Methods, Instruments, \& Computers 36, no. 4: 717-731.

Prieto, L. R., and E. M. Altmaier, 1994. "The relationship of prior training and previous teaching experience to self-efficacy among graduate teaching assistants." Research in Higher Education 35, no. 4: 481-497. 
Ramsden, P., and I. Moses. 1992. "Association between research and teaching in Australian higher education.” Higher Education 23, no. 3: 273-295.

Robertson, J. 2007. 'Beyond the 'Research/Teaching Nexus': Exploring the complexity of academic experience." Studies in Higher Education 32, no. 5: 541-556.

Robertson, J., and C. Bond, 2005. "The Research/Teaching Relation: A view from the 'Edge'.” Higher Education 50, no. 3: 509-535.

Salerno, C. 2004. What we know about the efficiency of higher education institutions: The best evidence. The Netherlands: The Center for Higher Education Policy Studies (University of Twente).

Sarrico, C. S., M. J. Rosa, P. N. Teixeira, and M. F. Cardoso 2010. “Assessing quality and evaluating performance in higher education: Worlds apart or complementary views?" Minerva 48, no. 1: 35-54.

Seldin, P. 2004. The teaching portfolio: A practical guide to improved performance and promotion/tenure decisions. Bolton, MA: Anker Publishing.

Seldin, P. 2006. Evaluating faculty performance: A practical guide to assessing teaching, research, and service. Bolton, MA: Anker Publishing.

Serow, R. C. 2000. "Research and teaching at a research university." Higher Education 40, no. 4: 449-463.

Shannon, D. M., D. J. Twale, and M. S. Moore. 1998. "TA teaching effectiveness: The impact of training and teaching experience." Journal of Higher Education 69, no. 4: 440-466.

Shin, J. C. 2011. "Teaching and research nexuses across faculty career stage, ability and affiliated discipline in a South Korean research university." Studies in Higher Education 36, no. 4: 485-503.

Sobel, M. E. 1982. “Asymptotic confidence intervals for indirect effects in structural equation models." Sociological Methodology 13, no. 1982: 290-312.

Taylor, J. 2007. “The Teaching:Research Nexus: A model for institutional management." Higher Education 54, no. 6: 867-884.

Teichler, U. 2014. "Teaching and research in Germany: The notions of university professors." In Teaching and research in contemporary higher education, edited by J.C. Shin, A. Arimoto, W.K. Cummings and U. Teichler, 61-87. Netherlands: Springer. 
Toutkoushian, R. K., S. R. Porter, C. Danielson, and P.R. Hollis. 2003. "Using publications counts to measure an institution's research productivity." Research in Higher Education 44, no. 2: 121-148.

Turner, D. (2005). "Benchmarking in universities: League tables revisited." Oxford Review of Education 31, no. 3: 353-371.

Tyagi, P., S. P. Yadav, and S. P. Singh. 2009. "Relative performance of academic departments using DEA with sensitivity analysis." Evaluation and Program Planning 32, no. 2: 168-177.

uz Zaman, M. Q. 2004. Review of the academic evidence on the relationship between teaching and research in higher education. London: Department for Education and Skills.

Van Raan, A. F. J. 2005. "Fatal attraction: Conceptual and methodological problems in the ranking of universities by bibliometric methods." Scientometrics 62 , no. 1: $133-143$.

Woodall, T., A. Hiller, and S. Resnick. 2014. "Making sense of higher education: Students as consumers and the value of the university experience." Studies in Higher Education 39, no. 1: 48-67.

Xiao, J., and S. Wilkins, 2015. "The effects of lecturer commitment on student perceptions of teaching quality and student satisfaction in Chinese Higher Education.” Journal of Higher Education Policy and Management 37, no. 1: 98110.

Zhao, X., J. G. Lynch, and Q. Chen. 2010. "Reconsidering Baron and Kenny: Myths and truths about mediation analysis." Journal of Consumer Research 37, no. 2: 197-206. 